\title{
A comunicação entre a família e a Instituição de Longa Permanência para Idosos*
}

\section{Communication between the Family and the Nursing Home}

\section{Resumo}

O objetivo deste artigo foi analisar os acoplamentos estruturais e as comunicações entre a Instituição de Longa Permanência para Idosos (ILPI) e a família. Trata-se de estudo qualitativo de cunho exploratório-descritivo baseado no método funcional de Niklas Luhmann. A coleta de dados foi realizada por meio de entrevista com dirigentes e idosos e de observação das comunicações nas ILPIs estudadas. Observou-se que a família, ao acoplar-se à ILPI, busca uma parceira no cuidado do idoso, e a instituição, por sua vez, espera da família a contrapartida no cuidado. A ILPI tenta assumir o papel de manutenção dos laços afetivos. Há dificuldade, contudo, de se considerar a família como cliente. Por falta de estratégias de inclusão, acaba-se por excluir a família do cotidiano das ações da instituição. Conclui-se aqui a necessidade de as ILPIs favorecerem vínculos mais significativos das famílias e de se estabelecerem sistemas interacionais mais efetivos.

\author{
Palavras-chave: \\ Instituição de Longa \\ Permanência para \\ idosos; idoso; \\ familia; afeto; \\ institucionalização; \\ teoria de sistemas
}

\section{Abstract}

The main goal of this article is to analyze the structural links and communication between the Nursing Home (NH) and the family. It is a qualitative and exploratory-descriptive study based on the functional method from Niklas Luhmann. Data collection has been performed throughout interview with managers, elderly people and the communication observation

Correspondência/Correspondence

Marion Creutzberg

Av. José Aloísio Filho, 965/63

90250-180, Porto Alegre, RS, Brasil

E-mail: marionc@pucrs.br

* As autoras são pesquisadoras que integram o Núcleo de Estudos do Envelhecimento da Universidade de Caxias do Sul. A pesquisa contou com a colaboração das bolsistas de Iniciação Científica: Nives Silva Sirena (CNPq) e Lisiane Besutti (BIC-UCS). 
at the NHs. It is observed that the family, when linked to the $\mathrm{NH}$, looks for a partner to take care of the old person. On the other hand, the institution expects the family's care for the aged person, too. The NH tries to maintain the affection ties. However, the problem is to consider the family as a client. The institution, due to lack of inclusion strategies, leaves the families out from their daily actions. The conclusion is that the NHs needs to establish more significant links and also more effective interactive systems with the families.
Key words: Homes for the aged ; aged; family; affect;

Institutionalization; systems theory

\section{INTRODUÇ̃̃̃O}

A insuficiência de programas públicos de cuidado domiciliar, a redução da disponibilidade de cuidado familiar e transferências intergeracionais no contexto urbano para a crescente proporção de idosos com incapacidades e fragilizados nas capitais brasileiras, ${ }^{4}$ moradias com espaço físico reduzido e estruturas com riscos para quedas e violências contra o idoso, dentre outros, são considerados fatores de risco para a institucionalização. ${ }^{9}$ A proporção de idosos em instituições de longa permanência para idosos (ILPIs) nos países em transição demográfica avançada chega a $11 \%,{ }^{8}$ enquanto que no Brasil não chega a $1,5 \%{ }^{7,14} \mathrm{~A}$ tendência é o aumento da demanda por ILPIs no Brasil, embora as políticas priorizem a família como signatária do cuidado ao idoso. Ainda que imbuídos dessa percepção, há um consenso de que, em muitos momentos, a ILPI se torna uma alternativa importante, devendo assegurar a qualidade de vida e satisfação, tanto dos idosos como de suas famílias.

A ILPI é considerada um sistema social organizacional. A complexidade alcançada nas sociedades funcionalmente diferenciadas desencadeia uma explosão de organizações para o desempenho de uma função social. Neste estudo, a análise da relação das ILPIs com o sistema familiar fundamentou-se no referencial explicativo-analítico de Niklas Luhmann, ${ }^{21}$ uma formulação atualizada da Teoria de Sistemas, com aplicações nos fenômenos sociais e culturais, com abordagem interdisciplinar. Os sistemas sociais organizacionais, como a ILPI, podem ser analisados em seus processos internos e as interdependências com outros sistemas. Esses sistemas são autopoiéticos e suas decisões se encontram em acoplamento estrutural permanente, por comunicações, com seu entorno.

A diferenciação funcional das sociedades contemporâneas afeta todas as áreas da experiência humana. $\mathrm{O}$ estabelecimento de um espaço mais delimitado, no qual a pessoa possa desenvolver e desempenhar suas qualidades individuais, surge como problema diante de um mundo tão complexo. Na sustentação de sua teoria e da família como um sistema social parcial, Luhmann entendia que amar e ser amado é necessidade básica na sobrevivência humana, ${ }^{21}$ e a família se especializa nesta questão, codifica estes sentimentos e os projeta ao ambiente social. A função da família é criar e manter um ambiente propício aos relacionamentos significativos. A família inclui a pes- 
soa na comunicação. Neste sentido, nenhum outro sistema parcial pode substituí-la. A comunicação na família tem relevância quando é uma comunicação íntima e pode ser perturbada pelos sistemas psíquicos, gerando ruídos no acoplamento estrutural. A família é um sistema histórico, sensível às mudanças internas e do entorno, levando à transformação das pessoas. Assim como outros sistemas, cada família tem uma organização e dinâmica própria, relacionada ao contexto históricosocial do ambiente, seguindo modelos de convivência e de acordo com a percepção dos indivíduos acerca da realidade. ${ }^{2}$

O cuidado à família tem sido considerado como a estratégia de cuidado à saúde das pessoas. A visão sistêmica é fundamental para a compreensão do conceito de saúde da família, de forma que o olhar Luhmanniano parece muito adequado, convergindo com os estudos sobre família. ${ }^{16,15}$ Os conceitos de família, em geral, referem-se ao viver em um lugar comum, ${ }^{5}$ dentre os requisitos para se considerar um grupo social como uma família.

Assim, no estudo do idoso institucionalizado é preciso entendê-lo tanto no contexto de sua família de origem, como no contexto de sua nova família, a instituição. Tal pressuposto levou-nos à definição do objetivo a seguir.

\section{OBJETIVO}

Analisar o sistema social organizacional - a ILPI e sua relação com o sistema familiar, identificando as comunicações que ocorrem nos acoplamentos estruturais entre a instituição e a família, e avaliando as ressonâncias do acoplamento estrutural sobre a família na instituição.

\section{METODOLOGIA}

Delineamento do estudo: estudo de abordagem exploratório-descritiva, com adoção da Teoria de Sistemas de Luhmann como método analítico, denominado método funcional. $^{21}$

Contexto do estudo: o estudo teve como foco a ILPI no contexto brasileiro, em meio urbano, com residentes sem condições de prover a própria subsistência ou provindas de famílias de baixa renda. Foram incluídas no estudo ILPIs conhecidas tradicionalmente como asilo de idosos, de caráter público ou privado e sem fins lucrativos.

\section{Procedimento de obtenção de dados:} a diversidade de observação proporciona maior aproximação à compreensão do problema. Nessa perspectiva, a observação das ILPIs foi realizada por observações de segunda e terceira ordem. ${ }^{21}$ A observação de segunda ordem é a auto-observação do sistema. Sua importância está no fato de o sistema observado poder ter funções latentes, não percebidas por ele próprio, mas que podem ser compreendidas pelo pesquisador. Foi realizada por meio de entrevista com sete profissionais dirigentes de diferentes subsistemas internos das ILPIs e oito idosos residentes em três ILPIs, da região metropolitana de Porto Alegre. Atendendo à diversidade de pontos de vista sobre o problema e acontecimentos 
apresentados sob diferentes circunstâncias, foram observadas comunicações produzidas por 52 ILPIs, veiculadas pela mídia e materiais de divulgação institucional. Tal material constitui expressão de operações internas, representando como as organizações se vêem. Expressa também expectativas do ambiente social em relação à organização. Já a observação de terceira ordem é aquela em que o pesquisador observa a produção artística e literária que tematiza a auto-observação de sistemas sociais. As investigações, em especial as descritivas, são consideradas fontes importantes para essa observação. Foi realizada a observação de 28 publicações nacionais identificadas por um levantamento em bases de dados, do período de 1998 a 2004, captandoas com os descritores "asilo", "asilo para idosos" e "institucionalização".

Análise dos dados: a análise dos dados de observações de segunda e terceira ordem teve a fundamentação pelo método de análise funcional de Niklas Luhmann, o qual adota o conceito de informação que serve para a identificação da complexidade, contingência e seleção. A análise funcional utiliza o processo de relação para a compreensão do existente como contingente, e do diverso como passível de comparação, permitindo identificar possibilidades de solução do problema. ${ }^{21}$ Para atender ao objetivo proposto, os dados foram analisados, identificando-se as operações de autopoiese e as contingências, os acoplamentos estruturais, as comunicações entre a ILPIs e o sistema familiar. Para o procedimento da análise funcional, optou-se pelo método de análise de conteúdo. ${ }^{26}$ No materi- al textual oriundo da transcrição das entrevistas, bem como da compilação impressa das comunicações de ILPIs, foi realizada, após organização e leitura exaustiva, a identificação das unidades de significado, que esteve fundamentada no referencial teórico adotado. Ao utilizar os dados provindos da observação das diversas fontes, ou seja, idosos, dirigentes, ILPIs, literatura e legislação, somados à experiência da pesquisadora, a análise foi, constantemente, resultado da triangulação de método adotado, o que constituiu um procedimento de validação dos resultados.

Cuidados éticos: o estudo foi submetido e aprovado pelo Comitê de Ética em Pesquisa da PUC-RS. Os dirigentes das ILPIs e os idosos residentes assinaram o Termo de Consentimento Livre e Esclarecido. Ainda nos dados obtidos nas comunicações de ILPIs, preservou-se a identidade da organização.

\section{aNÁlLSE E INTERPRETAÇÃO dOS RESULTADOS}

As observações do acoplamento estrutural entre a ILPI e a família foram organizadas em temáticas: da parceria entre a instituição e a família; o idoso e a família de origem; a instituição como nova família.

\section{A instituição e a família: parceiras no cuidado?}

A ILPI busca na família, a priori, uma parceira no cuidado. Pode-se afirmar que esta é a expectativa da instituição, ainda que não se- 
jam expressas tão claramente nem implementadas, com a necessária rapidez, estratégias que avancem neste sentido. Por outro lado, é preciso lembrar que a família, incluindo o próprio idoso, é que busca a ILPI como parceira nas demandas de cuidado. Ao acoplar-se à ILPI, a família busca a extensão de si mesma para cuidar adequadamente de seu idoso. ${ }^{31} \mathrm{O}$ momento do primeiro encontro desses três sistemas (idoso, família e ILPI) em geral acontece num clima de indecisões, culpa e insegurança. Portanto, estabelecer um compromisso e sentimento de parceria entre eles poderá ser determinante para o curso bem-sucedido da mudança do idoso para uma instituição. O envolvimento transparente e uma relação de horizontalidade permitiria a minimização de sentimentos negativos, especialmente para a família e o idoso. Por outro lado, a instituição tem a oportunidade de conhecer melhor o contexto familiar e, com isto, promover uma acolhida e assistência que atendam às necessidades e expectativas da família.

A observação demonstrou que a parceria nem sempre é possível e efetiva. Infere-se que isto esteja relacionado ao processo de institucionalização "mal trabalhado" pela ILPI, de um lado, e "mal elaborado" pela família, de outro. Contudo, é a ILPI que, após a institucionalização, procura (re)estabelecer a parceria, quando esta não acontece naturalmente. Há situações em que a legislação contribui para a manutenção ou recuperação da presença do familiar junto ao idoso: "Isso eu achei bastan- te interessante por parte de alguns familiares que quando saiu o Estatuto começaram a ligar pra cá e preocupados, 'mas eu não abandonei o idoso', houve uma [mudança] nesse sentido”. (D7)*

Embora a instituição se proponha a incluir a família, não pode obrigá-la a fazê-lo. Pode, sim, motivá-la, desde que haja um preparo para a integração da família, também nas diferentes equipes da instituição. A equipe de cuidado sofre com a solidão do idoso, com a falta que ele sente de sua família. ${ }^{22}$ De certa forma isto os leva a culpabilizar a família e, por isto, não incluí-la no cuidado. É como se, ao assumir o cuidado, o cuidador destituísse a família dessa possibilidade. Expressou uma dirigente: "Não tem como cobrar. Isso tem que ser uma coisa espontânea. Participa nas festividades, aí que eles vêm”. (D1).

Essa exclusão do familiar no cuidado, após o ingresso, foi verificada em estudos norteamericanos. ${ }^{30}$ Foi identificada a sensação de o familiar não ter o que fazer na ILPI, nem durante os momentos de visita, o que acaba por diminuir sua freqüência e torná-las "bem social assim, nada de participativo” (D1). Por outro lado, outros estudos perceberam que a participação dos familiares no cuidado tem efeitos positivos, especialmente quando se trata de filhos. A competência dos familiares na identificação das necessidades do idoso é evidente $^{20} \mathrm{e}$, em alguns casos, se mostram mais capazes que a própria equipe de enfermagem.

Foram incluídos trechos das comunicações, a fim de aproximar o leitor dos dados coletados. Os dirigentes são identificados pela letra "D", idosos por "I" e as Instituições por "ILPI". 
Nesse caso, entende-se que a inclusão do familiar, caso seja de seu desejo, é fundamental para a qualidade do cuidado.

A transferência de apoio funcional (atividades funcionais da vida diária - AFVDs, que incluem o banho, o vestir-se, alimentar-se, caminhar, ir ao banheiro) e instrumental (atividades instrumentais da vida diária - AIVDs, como fazer compras ou cuidar do dinheiro) é solicitada aos familiares ou significantes, por ocasião do ingresso na ILPI. Expressa a dirigente: "A gente sempre pede que tenha um responsável quando pode que possa nos ajudar, se tiver que levar no médico, especialista fora da instituição, de vez em quando buscar prá passear" (D2). A observação demonstrou que o apoio funcional e instrumental é esporádico. Pelo fato de depositarem na instituição a tarefa de cuidar, as famílias não se envolvem no auxilio funcional. Em vista de suas condições socioeconômicas, possivelmente o auxílio material e instrumental recebido pelos idosos institucionalizados, neste estudo, seja inferior ao descrito em estudos com idosos não-institucionalizados. ${ }^{28}$ Os estudos em ILPIs indicam diferentes situações, que vão de nenhum auxílio material por parte da família, até os dados de que $20 \%$ dos idosos recebem auxílio material de seus familiares. ${ }^{12}$

Ainda assim, a integração da família nos eventos é uma estratégia de aproximação. Os familiares são convidados a participar das festas de aniversário, datas festivas, atividades de lazer e integração. "Quando tem eventos eles participam junto com os idosos" (D5). "A família tem espaço quando ela é convidada pra participar dos eventos. Eu sempre pro- curo marcar eventos, atividades pra que a família participe e que o idoso tenha essa alegria de poder contar com a família junto"(D2).

Os dirigentes percebem que, apesar de incipiente, a interação com a familia já tem sido trabalhada na ILPI: "Se o idoso está um pouco mais deprimido a gente chama um familiar e, em casos muito extremos, colocamos na kombi e eu vou fazer uma visita assistida. Ele vai pra casa e vai visitar aquela família. Mas a gente não tem feito muito isso, geralmente com um pouco de diálogo, a família vem” (D6).

Por outro lado, indicaram limites existentes na ILPI à participação da família. Um deles, ainda presente, é a restrição de horário para as visitas dos familiares, expressa nas comunicações: "As visitas aos internos podem ser feitas das $12 \mathrm{~h}$ às $16 \mathrm{~h}$, diariamente"(ILPI3). "Essa parte de qualquer horário, ainda não. Existem restrições, algumas coisas que acho que tem que mudar bastante na instituição" (D2). Há expressões de que a família poderia ser peça-chave para a qualificação do cuidado, especialmente no que tange aos cuidados diretos: "Eu acho que se a família pudesse se responsabilizar um pouco também e nos ajudar, os funcionários na área da enfermagem, pudesse somar, eu acho que seria isso muito importante, bem significativo”(D2).

As observações citadas, acerca da participação da família, se movimentam entre limites e possibilidades. Essa certa contradição também é verificada na literatura nacional e internacional, a respeito da relação entre a família cuidadora e a ILPI. A família, junto com seu idoso, deve ser o foco da instituição. Ela 
também é o cliente, na situação da institucionalização permanente de seu familiar. $\mathrm{O}$ papel da família precisa ser definido a partir da concepção de que ela integra a equipe interdisciplinar e, por isso, pode ser envolvida no planejamento e execução do cuidado. Mas, ressalta a literatura, que se a família não quiser, isso deve ser respeitado e a ILPI pode colocar-se à disposição para auxiliar num caminho de aproximação. ${ }^{30,17}$

\section{0 idoso e a família de origem}

$\mathrm{Na}$ observação da fala das pessoas idosas, bem como dos dirigentes, foi possível perceber que a relação entre o idoso e a família é diversificada. Evidenciam-se tanto aqueles que mantêm (ou retomam) relacionamentos significativos com seus familiares, cuja base de comunicação é o amor, como aqueles que, por circunstâncias diversas, romperam os vínculos, ou mantêm uma comunicação ruidosa. ${ }^{21}$

Os idosos referem-se às relações com sua família de origem, ressaltando as pessoas com as quais mantêm vínculos significativos. Chama a atenção que a relação se dá, principalmente, com a vinda das pessoas até a ILPI. Ou seja, o idoso considera como vínculo mantido, considera-se como importante para o outro, quando ele é visitado pelos significantes, na instituição, que é o seu novo espaço de ser e viver: "Minha nora é muito boa, uma santa, todas quintas-feiras tá aqui, me visita sempre” (I6). "Tem bastante relação, tem muita visita, tanto os parentes como as pessoas, eles vêm aqui passear.Tem muita amizade” (I2).
A presença semanal de familiares de uma parte dos idosos é ressaltada pela ILPI: aproximadamente $25 \%$ recebem visita semanal de seus familiares (ILPI1). Na literatura acerca do tema, identificou-se que $67 \%$ dos idosos afirmam receber visitas de seus parentes, ${ }^{12}$ que o relacionamento com as famílias é considerado bom pela maioria dos idosos, e que, para $48 \%$ dos idosos, o relacionamento com os familiares é positivo. ${ }^{17} \mathrm{O}$ estudo de Mazo, Benedetti (1999) indicou que a proporção de idosos que têm muito pouco ou nada de contato com seus parentes é menor em relação aos que o têm. Apesar dessa constatação, a ausência foi ressaltada pelos dirigentes na ILPI: "Eu acho eles muito ausentes, eu acho que eles não têm participação com o seu familiar”(D1).

A ausência de familiares, ou a presença de apenas parte dos familiares, foi observada também em situações de idosos fragilizados que são mantidos em suas famílias. Estudos com cuidadores, ${ }^{19,9,3}$ familiares ou não, demonstram que estes ficam freqüentemente sozinhos na tarefa de cuidar e vivem na expectativa de receber ajuda, especialmente de outros familiares. Isto indica que, de certa forma, a distância não se dá somente em condições de institucionalização e nem somente as famílias que permitem a institucionalização deixam de participar da vida do idoso.

A ILPI, diante da ausência e apatia do familiar junto ao idoso na instituição, não fica omissa. Procura (re)estabelecer contatos, como já mencionado, entendendo que eles são fundamentais para o bem-estar do idoso: "Algumas famílias precisam ser convocadas 
para visitas, pois o afastamento prolongado ocasiona depressão, angústia e solidão no idoso, que se sente abandonado" (ILPI1). A fala de uma dirigente indica a importância da compreensão do contexto da família para entender que a demora entre uma visita e outra não é, necessariamente, falta de atenção e afeto pelo familiar idoso institucionalizado. Nesse sentido Stevens, Walsh, Baldwin ${ }^{30}$ apontaram que identificar os motivos da não-participação pode levar à minimização dos mesmos, assim como à compreensão da situação da família, sem o risco de reforçar sentimentos de culpa e fracasso, muito freqüentes entre familiares.

Fontoura identificou que $40 \%$ dos idosos sentem que, com o ingresso na ILPI, perderam tudo, inclusive os vínculos. A perda dos vínculos com a família ocasiona a expressão freqüente de ressentimento, por parte dos idosos: "Falta é visita, é os familiares aparecerem aqui e fazer a visita pra gente, isso que é preciso" (I5). A perda ou o enfraquecimento dos vínculos pode estar associada com o tipo de relação anterior à institucionalização. Há situações em que os filhos se ressentem daquilo que tiveram de seus pais ao longo da vida: " "Tem gente que diz assim: tudo o que vocês precisarem podem me telefonar que eu levo, agora não me peçam pra ir conversar com ele, dar amor, porque ele nunca me deu isso"(D3). Em outros momentos os pais, institucionalizados, referem-se ao passado com sentimento de culpa: "Talvez porque fui um bom marido, mas péssimo pai para meus filhos"(ILPI8).

Mas também não faltam relatos de maustratos, negligência ou abandono. Isto é observado à semelhança do que outros estudos têm descrito. Ao contrário do que se supõe no senso comum, não é em ILPI, mas no ambiente doméstico que são identificados os maiores abusos e negligências, seja pelo choque de gerações, pelo diminuto espaço físico ou pelas carências, somados à visão da velhice como decadência. ${ }^{24,13,11}$ Elsen ${ }^{15}$ aponta as relações intergeracionais conflituosas e o aporte econômico e social insuficiente como principais fatores desencadeantes de maus-tratos ao idoso. A fragilização da saúde do cuidador, pela exaustão física e mental, no caso de idoso com necessidades de cuidado, também é um fator contributivo: "Ela estava sendo cuidada por um cunhado que batia nela, não alimentava”(D7).

É preciso enfatizar a impossibilidade de fazer disto uma generalização, erro que é freqüente nas análises, seja em pesquisas, seja no ambiente societal. Ao contrário do senso comum, a maior parte dos idosos não foi abandonada pela família. "Não é possível sempre qualificar a família como vilã e o velho como vítima". ${ }^{1}$ Esta preocupação é apontada e pode ser exemplificada na fala da dirigente: "A família não veio porque ela é ruim, que ela vai fazer outras coisas, que é essa a imagem da sociedade civil e do asilo, que a família é (des)humana e colocou ela lá por um ímpeto de maldade e desapego desse idoso" (D6) .

A institucionalização pode se dar pelo fato de a família considerar a presença do idoso como uma sobrecarga, um peso, tanto em situações em que o vínculo afetivo é positivo, quanto em vínculos negativos. Fontoura ${ }^{17}$ constatou que $64 \%$ das familias sentiram-se aliviadas, positivamente, após o ingresso do idoso 
na ILPI, ainda que $50 \%$ dos familiares refiram que o melhor lugar para o idoso é a vida com sua familia e seus pertences. Ramos ${ }^{27}$ identificou, em sua revisão, que o sentimento de peso pode estar relacionado à valorização extrema da produtividade na sociedade ocidental e à desvalorização do cuidado ao idoso.

Os conflitos intergeracionais são realidades nas famílias. Estudos têm-se ocupado com este assunto, indicando que a diminuição das interações entre os idosos e as gerações mais novas pode ser causa da exclusão dos mais velhos, quando da ausência de valorização mútua entre as gerações: ${ }^{27}$ "Os conflitos nessas últimas duas décadas são incríveis, de relacionamento de adolescentes, até com os pais é difícil, imagina com os avós” (D3). Especialmente em situações de dependência, seja ela material, instrumental ou funcional, o sentimento de carga poderá ser maior. Estudos que se fundamentam na reciprocidade como fator de satisfação pessoal indicam que problemas de saúde e a baixa renda de idosos "tendem a aumentar a dependência e a reduzir a capacidade de retribuir o suporte fornecido por outras pessoas", ${ }^{27}$ contribuindo com a sensação de estar atrapalhando os familiares.

Karsch enfatizou a importância da preservação do cuidado do idoso no domićlío da família. No entanto, afirma que "cuidar de um indivíduo idoso e incapacitado durante 24 horas, sem pausa, não é tarefa para uma mulher sozinha, geralmente com mais de 50 anos". ${ }^{19}$ Para isto há que se ter serviços para atender a suas necessidades, e políticas de proteção para assumir esse papel.
A inclusão do idoso na família é um assunto a ser discutido muito, ainda, no ambiente societal: "Tem que ser muito mais discutido. Porque se de repente o meu idoso lá em casa envelheceu, está com um probleminha de saúde, está dando trabalho, ele não se torna descartável, ele faz parte daquela família" (D7). Levanta-se a discussão sobre a incipiente rede de suporte comunitário ou outras alternativas a serem oferecidas à família, diante das dificuldades que ela encontra ao cuidar de seu idoso.

A referência à opção pela institucionalização motivada pela dificuldade ou impossibilidade de morar junto com os filhos é comum. Saad ${ }^{28}$ ressaltou que, em vista da situação econômica das famílias brasileiras, há dificuldade em oferecer auxílio, sobretudo material, aos familiares idosos, o que é confirmado em estudos com famílias de idosos institucionalizados. ${ }^{17,1}$ Saad referiu-se à conjuntura brasileira como restritiva à transferência de ajuda de filhos adultos para pais idosos.

Para "36\% das familias de um estudo, a institucionalização minimizou problemas financeiros que tinham com os idosos em casa, devido aos gastos elevados com alimentação, saúde, medicamentos". ${ }^{17}$ Algumas vezes a institucionalização, frente a essas situações, acontece de maneira tranqüila, auxiliando na manutenção dos vínculos e da saúde da família, incluindo o próprio idoso. Pode significar, também, um momento de ajuste de contas. Nem sempre representará tristeza, desamparo ou abandono. Na maior parte das vezes, ainda é o idoso quem decide pela mudança para uma ILPI. Bulla e Mediondo ${ }^{6}$ identificaram que apenas $16 \%$ dos idosos referi- 
ram ter ingressado por decisão de terceiros, enquanto $51 \%$ fizeram, eles próprios, a opção pela institucionalização. A fala seguinte ilustra essa satisfação que acompanha muitos idosos que vivem em instituições: "Tirei férias de minha família que já tarde decidiu me trazer aqui e deixar de pegar tanto no meu pé" (ILPI33).

Em um estudo, $62 \%$ dos idosos informaram que não gostariam de estar com seus familiares, a maioria indicando gostar da instituição, embora também haja quem diga que ninguém o quer fora da ILPI. ${ }^{12}$ A satisfação referida pelos idosos pode ser vista como resignação ou como uma forma de defesa para defender-se da dor, e que o real prazer em encontrar-se na instituição seria uma exceção à regra. Entende-se que tais processos de resignação podem estar presentes em alguns idosos, mas não podem ser tomados como um pressuposto generalizado. Em algumas situações, podem permanecer a mágoa, o sentimento de exclusão, de não-pertença à família. Possivelmente isso aconteça mais freqüentemente nos casos em que a decisão não tenha sido compartilhada com o idoso. Mesmo em condições adversas, a decisão pode ser "umprocesso de crescimento para a familia, com todos aproveitando a oportunidade impar de desenvolver sentimentos mais autênticos e legitimos". ${ }^{31}$

Apesar da preocupação com a restrição da transferência de apoio intergeracional nas famílias brasileiras, os estudos demonstram um crescimento de uma via de mão dupla nas transferências entre adultos e idosos. ${ }^{28}$ Talvez a parcela de idosos institucionalizados permaneça na impossibilidade da dupla via de apoio.
Nesse sentido, a expectativa das ILPI é manter, ao máximo, o apoio de netos, filhos e demais pessoas significativas para os idosos, já que a instituição assume parte de suas necessidades, a começar pelo lugar para morar. Assim, a manutenção dos vínculos com a família é motivada e aprovada pelas ILPIs: "Nós temos um idoso que mora aqui, mas no verão ele vai pra praia, fica com a família na praia, a família tem uma casinha na praia" (D6). Mesmo diante de famílias com história de maus-tratos ou negligência, procura-se resgatar vínculos: "O que a gente observa no diaa-dia com o idoso que quando ele tem alguém lá fora, que ele consegue manter um certo vínculo, ele fica melhor, ele se dá melhor, então a gente sempre procura buscar pra que as pessoas venham fazer as visitas" (D7).

\section{A instituição como nova família}

A observação e a literatura têm demonstrado que, muitas vezes, o idoso procura uma instituição desejando encontrar novas possibilidades de vida, segurança, respeito e assistência em suas necessidades. "Busca a inserção em uma comunidade que o estimule a construção de uma nova identidade e permita uma sensação de pertencimento". ${ }^{31}$ Essa expectativa pode ser respondida na medida em que, num processo de dupla contingência, a instituição favorece o estabelecimento de vínculos significativos e de sistemas interacionais, minimizando quaisquer sentimentos de desamparo ou conflitos anteriores à institucionalização. A pessoa pode sentir-se tão bem, ou melhor do que com a família de origem: "De localidades e com histórias de vida diferentes, os idosos do Lar são 
parte de uma grande família, unida pelos laços de solidariedade"(ILPI30).

Isto, no entanto, não se dá somente pelo aumento de possibilidades relacionais. Promover o envolvimento mútuo e voluntário nas interações é determinante no bem-estar e satisfação das pessoas, e é parte da função essencial da ILPI. Esse fator foi intensamente abordado pelos idosos, ao falarem da vida na instituição: "Estou aqui há quatro anos e pra mim melhor não existe, pra mim é ótimo estar aqui, me sinto muito bem" (I1). "Vai fazer dois anos que eu estou aqui e a gente já fez bastante amizade, eu me dou com todo pessoal que tem aqui dentro" (I8). "Estou realizada, eu gosto muito daqui e tudo" (I2). "Ela está ótima, pra mim está tudo bem, eu aqui moro num quarto sozinha com uma colega. Duas camas. Tenho cama boa, tenho comida boa, tem tudo, o que a gente mais quer? Eu não quero mais nada, não" (I6).

A literatura revisada por Ramos ${ }^{27}$ demonstrou que as relações de idosos com amigos apresentaram maior reciprocidade do que as relações com parentes. Mazo e Benedetti ${ }^{23} \mathrm{ci}-$ tam que a satisfação e o bem-estar físico e psicológico em compartilhar o cotidiano com amigos são maiores do que a vivência compulsória com os filhos. A possibilidade de encontrar satisfação na ILPI foi evidenciada na fala da idosa, que poderia, se quisesse, voltar para a casa do filho: "Eu não queria mais ir pra fora, só quando eu morrer. Daqui eu não saio mais, apesar de que a minha nora ela tem o quarto meu reservado lá, com cama tudo" (I6). O cotidiano compartilhado com pessoas que possuem experiências da mesma época possibilita o estabelecimento de novas amizades, dito pelos idosos, com muita força, pela expressão "pegar amizade" (I7).

Algumas situações familiares de distanciamento levam a instituição a assumir, definitivamente, o papel de nova família, em todas as dimensões da vida: “Às vezes o pessoal diz: 'não adianta me telefonar, eu não posso, eu estou doente'. O que nós podemos fazer, a família não está mais dando atenção, não adianta ir prá delegacia do idoso, não adianta denunciar, aí a gente acaba fazendo a parte que a família não faz" (D3). "O Asilo tem sido o verdadeiro lar de pessoas que não abrem mão da dignidade e que muitas vezes foram esquecidas até mesmo por parentes bem próximos, como os filhos" (ILPI3).

O ambiente familiar da instituição traz a segurança que disseram não encontrar mais no entorno: "O que eu acho é que aí fora está muito pior, aqui dentro a gente está bem. Aí fora é um perigo de vida e miséria" (I7).

A superação da distância ou até mesmo da ausência cotidiana da família de origem pode ser favorecida quando se possibilita uma rotina pessoal semelhante àquela que a pessoa tinha no seu ambiente anterior. No entanto, os estudos revisados que abordam a rotina das ILPIs observaram que essa, em geral, é bastante rígida, dificultando uma continuidade à rotina anterior, no que se refere aos horários da alimentação, de visitas, de banho, de dormir, dentre outros. ${ }^{12,32,23}$ Entende-se que a necessidade de organizar horários está relacionada a outros fatores, como os horários dos funcionários, por exemplo. Mas há aspectos 
que podem, se esta for a concepção da equipe, ser adequados às preferências dos idosos.

A observação e a literatura evidenciam que há um grupo significativo de idosos, nas ILPIs, que não constituíram família, do ponto de vista de parentesco. Bulla e Mediondo ${ }^{6}$ verificaram que $36 \%$ dos idosos não tiveram filhos; Herédia, Cortelletti, Casara ${ }^{18}$ observaram que apenas $42,99 \%$ têm filhos. Para estes, a instituição acaba significando, mais ainda, uma possibilidade de vida em família: "A grande maioria teve um companheiro ou companheira e não tiveram filhos. Tem, às vezes, um irmão que não sabe nem onde se encontra, esqueceu até o nome. A família deles passa a ser colegas e os funcionários da casa" (D7). Ra$\operatorname{mos}^{27}$ identificou que, entre os idosos que não constituíram família, o suporte emocional é a necessidade básica menos alcançada ao longo da vida, o que pode representar uma ameaça à qualidade de vida. Neste sentido, fica reforçada a necessidade de a ILPI responder às necessidades e expectativas por meio do desenvolvimento de vínculos significativos. Mas também nessa nova família há amizades e inimizades, amores e conflitos: "O que aqui dentro tem, às vezes, é muita conversa um do outro, gente de idade, não tem mais o que fazer" (I8). "Eles encontram formas de se relacionar, de ter amizades, namoros, como inimizades também" (ILPI24).

\section{CONSIDERAÇÕES FINAIS}

Observa-se, no contexto brasileiro, que a integração da família não tem sido um programa interno da ILPI, sistematicamente de- senvolvido e envolvendo os diversos subsistemas da organização. Portanto, há que se encontrar alternativas para a inclusão desse importante recurso, e conseqüente ressonância na ILPI, com a qualificação do cuidado ao idoso.

Percebeu-se que na ILPI não apenas é acusada ou lamentada a falta da família. Há uma busca, ainda que tímida, pela manutenção dos vínculos entre o idoso e sua família de origem. Tal motivação já indica, em parte, a consideração do binômio idoso-família como foco do cuidado na instituição.

Por mais que a ILPI procure re(fazer) e proporcionar uma vida familiar, ela é diferente. Mas, talvez, nem pior, nem melhor. A pretensão da ILPI não pode ser a de substituir a família, mas de se entender como ampliação da família, com laços e vínculos igualmente significativos.

\section{NOTAS}

Enfermeira, Doutora em Gerontologia Biomédica, Professora Adjunta na Faculdade de Enfermagem, Nutrição e Fisioterapia, Pontifícia Universidade Católica do Rio Grande do Sul. Porto Alegre, RS, Brasil E-mail: marionc@pucrs.br

b Enfermeira,Doutora em Enfermagem, Professora Titular no Departamento de Enfermagem, Universidade Federal de Santa Catarina. Florianópolis, SC, Brasil E-mail: lucia@nfr.ufsc.br; lucia.ltakase@pesquisador. cnpq.br

c Sociólogo, Doutor em Sociologia. Professor Adjunto na Faculdade de Filosofia e Ciências Humanas, Pontifícia Universidade Católica do Rio Grande do Sul. Porto Alegre, RS, Brasil E-mail: sobottka@pucrs.br

d Enfermeira, Doutora em Educação, Professora Adjunta na Faculdade de Enfermagem, Nutrição e Fisioterapia, Pontifícia Universidade Católica do Rio Grande do Sul. Porto Alegre, RS, Brasil E-mail: santoslara@pucrs.br 


\section{REFERÊNCIAS}

1. Alcântara AO. Velhos institucionalizados e família: entre abafos e desabafos. [dissertação]. Campinas: Universidade de Campinas; 2003.

2. Althoff CR. Dimensionando o espaço da família, no âmbito do público e do privado. Cogitare Enfermagem 1996 jul./dez; 2(2): 35-8.

3. Alvarez AM. Tendo que cuidar: a vivência do idoso e de sua família cuidadora no processo de cuidar e ser cuidado em contexto domiciliar. Florianópolis: UFSC; 2001.

4. Born T, Boechat NS. A qualidade dos cuidados ao idoso institucionalizado. In: Freitas VF, et al. Tratado de Geriatria e Gerontologia. Rio de Janeiro: Guanabara Koogan, 2002. p.768-77.

5. Boyd S. Base conceptual para la intervencion de enfermeria com las familias. In: Hall J, Weaver B, organizadoras. Enfermeria en salud comunitaria: un enfoque de sistemas. Washington: OPAS; 1990.

6. Bulla LC, Mediondo MZ. Velhice, dependência e vida cotidiana institucional. In: Cortelletti IA, Casara MB, Herédia VBM, organizadoras. Idoso asilado: um estudo gerontológico. Caxias do Sul, RS: EDUCS, EDIPUCRS; 2004.

7. Camarano AA. Brazilian population ageing: differences in well-being by rural and urban areas. IPEA. Texto Para Discussão [online] Maio 2002. [33 Telas] Disponível em: URL: http://www.ipea.gov.br.

8. Chaimowicz F, Greco DB. Dinâmica da institucionalização de idosos em Belo Horizonte, Brasil. Rev Saúde Pública [Online], 1999 Out;33(5) [8 Telas]. Disponível em: URL: http:/ / www.fsp.usp.br/rsp.
9. Creutzberg M, Santos BRL. Famílias cuidadoras de pessoa idosa: relação com instituições sociais e de saúde. Rev Bras Enferm 2003 nov./dez; 56( 6) 624-9.

10. Creutzberg M, Santos BRL. Se a gente não tem família, não tem vida: subsídios para o cuidado de enfermagem domiciliar. Rev Gaucha Enferm 2000; 21(n. esp): 101-2,

11. Cruz JMO, Fontes MR, Santos JMJ, Bergo MSAA. Cuidados com idosos: percepção de idosos e de profissionais de saúde sobre maus tratos no espaço familiar. Textos Envelhecimento. [periódico online] 2003 Set. [ acesso 2004 Set 9] 6(2) [15 Telas]. Disponível em: URL:http:/ / www.unati.uerj.br/tse/ scielo.php?script $=$ sci_arttext\&pid $=$ s1517$59282003000200005 \& \operatorname{lng}=$ pt\&nrm=isso.

12. Davim RMB, et al. Estudo com idosos de instituições asilares no município de Natal(RN): características socioeconômicas e de saúde. Revista Latinoamericana de Enfermagem 2004 maio/jun; 12(3): 518-24.

13. Debert GG. A família e as novas políticas sociais no contexto brasileiro: interseções. Revista Estudos Interdisciplinares 2001; 3(2): 71-92.

14. Duarte MJRS. Autocuidado para a qualidade de vida. In: Caldas CP. A saúde do idoso: a arte de cuidar. Rio de Janeiro: Eduerj; 1998. p.18-34.

15. Elsen I. A família: uma unidade de cuidados na saúde e na doença. In: Elsen, I., Marcon, S.S.; Silva, M.R.S. O viver em família e sua interface com a saúde e a doença. Maringá (Pr): Eduem; 2002. p. 11-24.

16. Elsen I. Desafios da enfermagem no cuidado de famílias. In: Elsen I; Penna CMM; Althoff CR, organizadores. Marcos para a prática de Enfermagem com famílias. Florianópolis: Editora UFSC; 1994. 
17. Fontoura EG. A vida asilar para idosos residentes e seus familiares: um estudo de representações sociais de uma instituição de Feira de Santana [dissertação] Salvador: Universidade Federal da Bahia, Escola de Enfermagem; 2003.

18. Herédia VBM, Cortelletti IA, Casara MB. O asilamento sob o olhar de histórias de vida. In: Cortelletti IA, Casara MB, Herédia VBM, organizadores. Idoso asilado: um estudo gerontológico. Caxias do Sul (RS): Educs, Edipucrs; 2004.

19. Karsch UM. Idosos dependentes: famílias e cuidadores. Cad Saúde Pública 2003 maio/ jun; 19(3): 861-6.

20. Lindgren CL, Murphy AM. Nurses' and family members' perceptions of nursing home residents' need. J Gerontol Nurs. 2002 Aug; 28(8): 45-53.

21. Luhmann N. Soziale systeme: grundriâ einer allgemeinen theorie. Frankfurt: Suhrkamp; 1984.

22. Martinez SHL. O significado do cuidado para quem cuida do idoso em uma instituição asilar. [dissertação] São Paulo: Universidade do Estado de São Paulo; 2003.

23. Mazo GZ, Benedetti TB. Rev Ciências Saúde, Florianópolis, v.18, n.1, p.51-56, jan./ dez., 1999.

24. Mazuim CHR. Idoso institucionalizado: suporte, abrigo ou segregação? [dissertação]. Porto Alegre: PUCRS, Faculdade de Serviço Social, 2004.

25. Minayo MCS. Violência contra idosos: relevância para um velho problema. Cad Saúde Pública. [periódico online], 2003 maio/jun [acesso 2004 jul 25]; 19(3): 783-91. Disponível em: URL: http:/ /www.scielo.br/ pdf/csp/v19n3/15881.pdf

26. Moraes R. Análise de Conteúdo: limites e possibilidades. In: Engers, Maria Emília, organizadora. Paradigmas e metodologias de pesquisa em educação. Porto Alegre: EDIPUCRS, 1994

27. Ramos MP. Apoio social e saúde entre idosos. Sociologias 2002 jan./jun; 4(7):156-75.

28. Saad PM. Transferências de apoio entre gerações no brasil: um estudo para são paulo e Fortaleza. In: Camarano AA, Organizador. Muito além dos 60: os novos idosos brasileiros. Rio De Janeiro: Ipea; 1999. p 251-80.

29. Savonitti BHRA. Qualidade de vida de idosos institucionalizados [dissertação] São Paulo: Universidade de São Paulo, Escola de Enfermagem; 2000

30. Stevens GL, Walsh RA, Baldwin BA. Family caregivers of institucionalized and noninstitucionalized elderly individuals. Nurs Clin North Am 1993 Jun; 28(2) 349-62.

31. Vieira EB. Instituições geriátricas: avanço ou retrocesso? Rio de Janeiro: Revinter; 2003.

32. Yamamoto A, Diogo MJD. Os Idosos E As Instituições asilares do município de Campinas. Revista Latinoamericana de Enfermagem 2002 Set./Out; 10( 5): 660-6.

Recebido em: 11/1/2007

Aceito: 26/5/2007 